\title{
Effect of Interferon- $\alpha$ on Experimental Septal Fibrosis of the Liver - Study with a New Model
}

\author{
Marcia Maria de Souza, Raymundo Paraná*, Christian Trepo**, \\ Aryon A Barbosa Jr, Irismar Oliveira*, Zilton A Andrade/ ${ }^{+}$
}

\author{
Centro de Pesquisas Gonçalo Moniz-Fiocruz, Rua Valdemar Falcão 121, 40295-001 Salvador, BA, Brasil \\ *Faculdade de Medicina, Universidade Federal da Bahia, Salvador, BA, Brasil \\ **INSERM Unité 271, Lyon, France
}

Interferon- $\alpha$ is used in antiviral therapy in humans, mainly for viral hepatitis $B$ and $C$. An anti-fibrotic effect of interferon has been postulated even in the absence of anti-viral response, which suggests that interferon directly inhibits fibrogenesis. Rats infected with the helminth Capillaria hepatica regularly develop diffuse septal fibrosis of the liver, which terminates in cirrhosis 40 days after inoculation.

The aim of this study was to test the anti-fibrotic effect of interferon in this experimental model. Evaluation of fibrosis was made by three separate methods: semi-quantitative histology, computerized morphometry and hydroxyproline measurements. Treatment with interferon- $\alpha$ proved to inhibit the development of fibrosis in this model, especially when doses of 500,000 and 800,000 IU were used for 60 days. Besides confirming the anti-fibrotic potential of interferon- $\alpha$ on a non-viral new experimental model of hepatic fibrosis, a clear-cut dose-dependent effect was observed.

Key words: interferon- $\alpha$ - hepatic fibrosis - Capillaria hepatica

Patients with chronic hepatitis, especially due to hepatitis $\mathrm{C}$, and presenting sustained responses to treatment with interferon- $\alpha$, exhibited quantitative improvement of the degree of hepatic fibrosis (Manabe et al. 1993, Shiratori et al. 2000). The decrease in the amount of fibrosis was recorded even in non-responders to the anti-viral treatment and was seen to occur regardless of viral load, and the presence of inflammatory or degenerative changes (Guerret et al. 1999). Nevertheless, it remains rather difficult to determine from such clinical studies whether the effect on fibrosis was indeed direct or merely secondary to modulatory and anti-viral properties of the drug.

The anti-fibrotic effect of interferon- $\alpha$ on nonviral conditions has been tested with different experimental models of hepatic fibrosis. Positive results were observed with the classical model of carbon tetrachloride-induced hepatic fibrosis in rats (Pilette et al. 1997). However, the model of total bile duct ligation in rats has yielded both positive and negative results (Moreno \& Muriel 1995).

\footnotetext{
Supported by Pronex.

${ }^{+}$Corresponding author. Fax: +55-71-356.2155. E-mail: zilton@cpqgm.fiocruz.br

Received 21 June 2000
}

Accepted 4 October 2000
When these two models were actually compared, interferon was seen to inhibit fibrosis due to $\mathrm{CCl} 4$ administration, but not that derived from total bile duct ligation (Fort et al. 1998). As a contribution to this subject, the present paper deals with the effects of interferon- $\alpha$ on a new model of hepatic fibrosis in rats. As first described by Ferreira and Andrade (1993), rats infected with the helminth Capillaria hepatica regularly develop septal fibrosis of the liver. Septal fibrosis starts one month after infection and is already well developed around the 40th day, when the worms have already died and the focal direct parasite-dependent lesions exhibit encapsulation and signs of progressive resorption. Septal fibrosis is progressive from then on, and the late outcome is a full picture of cirrhosis. The histology is similar to that observed in rats repeatedly injected with whole pig serum, except for the presence of focal $C$. hepatica lesions (Paronetto \& Popper 1966, Andrade 1991). Moreover, similar to the pig-serum model, septal fibrosis in capillariasis is not preceded by diffuse chronic inflammation or overt hepatocellular necrosis. Its pathogenesis has probably an immunological basis, as demonstrated for the pig-serum model (Bhunchet 1996). Antigenic materials sequestered within the focal parasitic lesions, being slowly released during prolonged periods of time, have been suspected as the main pathogenic factor in hepatic fibrosis associated with $C$. hepatica infection in rats. 
This new experimental model was used in the present study to test the effects of interferon$\alpha$ on hepatic fibrosis.

\section{MATERIALS AND METHODS}

Adult Wistar rats of both sexes, weighing 170 to $300 \mathrm{~g}$, were maintained on a commercial balanced diet and water ad libitum. They were infected with approximately 800 embryonated eggs of $C$. hepatica, administered by gavage. Twenty-five days after inoculation the animals were divided into four groups of five animals each, according to type and dose of treatment. Groups I, II and III were treated with subcutaneous injections of $0.5 \mathrm{ml}$ of interferon- $\alpha$ in saline, administered daily in the doses of 100,000, 500,000 and 800,000 IU, respectively. The fourth group was used as control, treated under the same schedule, but with saline injections only. An hybrid, recombinant, non-species specific interferon- $\alpha$, formed by an $\mathrm{N}$-terminal segment composed by the aminoacids $1-60 \mathrm{HuIFN}-\alpha \mathrm{B}$ and 61-166 HuIFN- $\alpha$ D, was used (Meister et al. 1986, Horisberger \& Staritky 1987).

Treatment was administered from the 25th to the 65th day of infection. To follow the course of treatment a surgical liver biopsy was performed on the 45th day of infection. Sacrifice of all animals occurred on the 95th day after inoculation.

Samples of the liver obtained by biopsy and necropsy were submitted to histological, morphometrical and biochemical studies. Histology was made on sections of Bouin-fixed tissue, embedded in paraffin, which were stained with hematoxylin and eosin and picrosirius-red for collagen, according to Junqueira et al. (1979). The degree of fibrosis was first evaluated with picrosirius-red stained slides, by means of a semiquantitative method, the sections being independently and blindly recorded by two observers. Fibrosis was arbitrarily recorded as (0) or absent (normal liver histology); mild (+) a few thin septa distributed in a few focal areas, usually around dead-worm lesions; moderate $(++)$ when septal fibrosis was diffuse, but the septa were thin, usually incomplete, terminating within the liver parenchyma; and severe (+++) with numerous septa of variable thickness, circumscribing parenchymal nodules (cirrhosis). In case of disagreement, a settlement was reached by re-examining the sections before decoding them.

Morphometric measurements were made on histological sections stained with the picrosiriusred method, and analyzed by means of a Computerized Image Analyzing System (Leica Quantimet Q500MC, Cambridge, England). For such measurements a total sectional area of $17.01 \times 10^{6} \mu \mathrm{m}^{2}$ per case was evaluated. A 4x objective (Microscope
Leica Microstar IV) was utilized in nine microscopic fields, randomly selected. The sectional area of the fibrous tissue, red stained, was directly measured and calculated as a percent of the total area examined.

Biochemical determination of hydroxyproline content was made according to the colorimetric method of Bergman and Loxley (1963).

Results were submitted to statistical analysis.

\section{RESULTS}

All infected control animals, that did not receive interferon, developed septal fibrosis of the liver, which was already well established by the 45th day of infection and that evolved toward a full picture of cirrhosis by the end of the experiment (Fig. 1). Fibrosis appeared as fine and long, thin, deeply sirius-red stained threads, formed along the acinar zone III and connecting central veins to central veins and also to portal spaces. In cases with marked degree of fibrosis the septa appeared thicker, exhibited condensation zones and presented numerous radiating branches that delimited nodular areas of parenchyma, connected central areas to portal spaces and sometimes ended abruptly within the hepatic parenchyma. The nodular zones of the hepatic parenchyma usually maintained its normal structure, with one-cell thick cords, but, later on, formed expansive regenerative nodules, with more than one-cell-thick cords (Fig. 2). Treatment with interferon considerably attenuated the degree of septal fibrosis. Although the fibrous septa still appeared circumscribing parenchymal nodules in some treated animals, these were focally distributed, usually in direct connection with focal dead-parasite lesions, and in none of them a complete morphological picture of cirrhosis was registered (Fig. 3).

The decrease in the amount of fibrosis appeared evident when the tissues were analyzed with semiquantitative histological (Table I), morphometrical (Table II) and biochemical (Table III) methods. A dose-dependent effect was observed. With the dose of $100,000 \mathrm{IU}$ the results were somewhat dubious. They did not reach statistical significance neither by measurement of hydroxyproline content, nor by the semi-quantitative histologic evaluation. However, morphometric measurements showed an antifibrotic effect, which was statistically significant Results refer to necropsy material, since the group treated with the dose of 100,000 IU of interferon has not been subject to a previous biopsy.

Significant results appeared when the doses of 500,000 IU and especially 800,000 IU were applied. These high doses apparently did not cause any ill effect for the animals. They maintained good appearance of the body hair, were active, did 


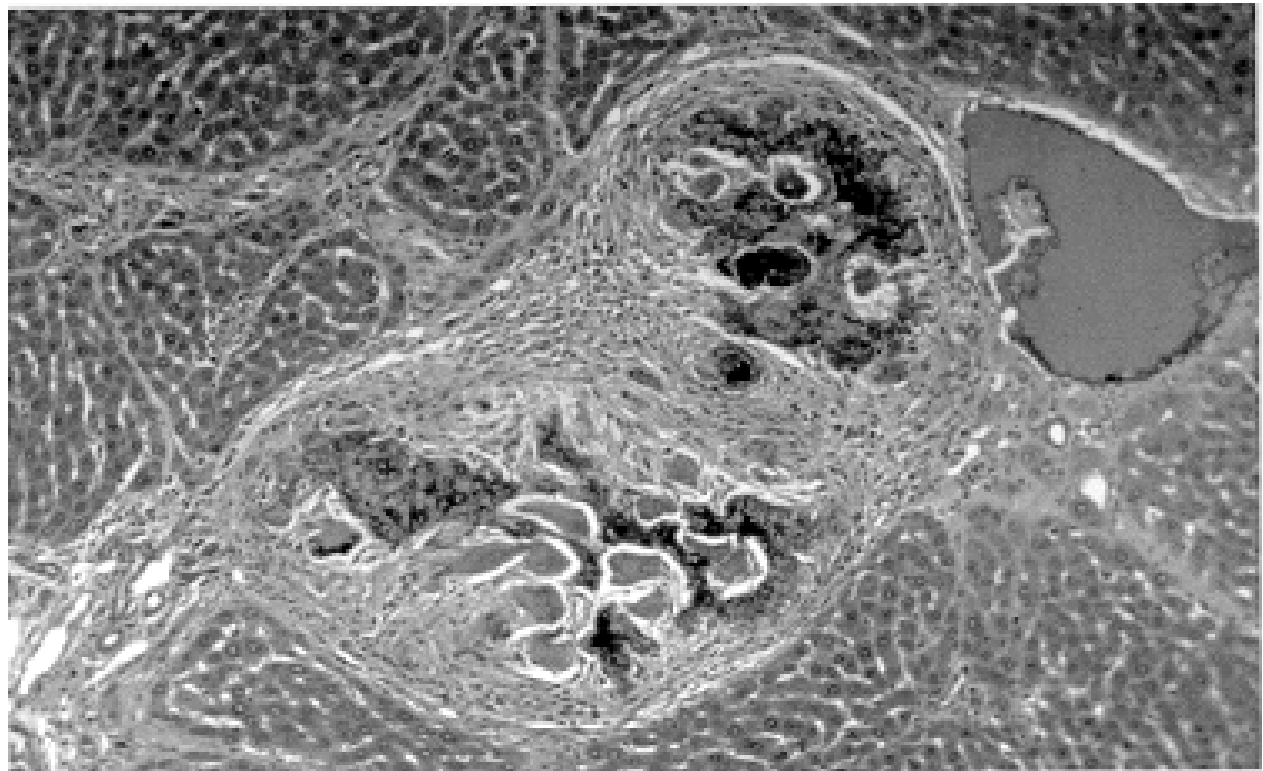

Fig. 1: focal lesion caused by Capillaria hepatica in the rat liver. Necrotic remnants of dead worms and eggs appear surrounded by an encapsulating fibrous reaction. The hepatic parenchyma is already dissected by thin fibrous septa. Hematoxylin and Eosin, 160X

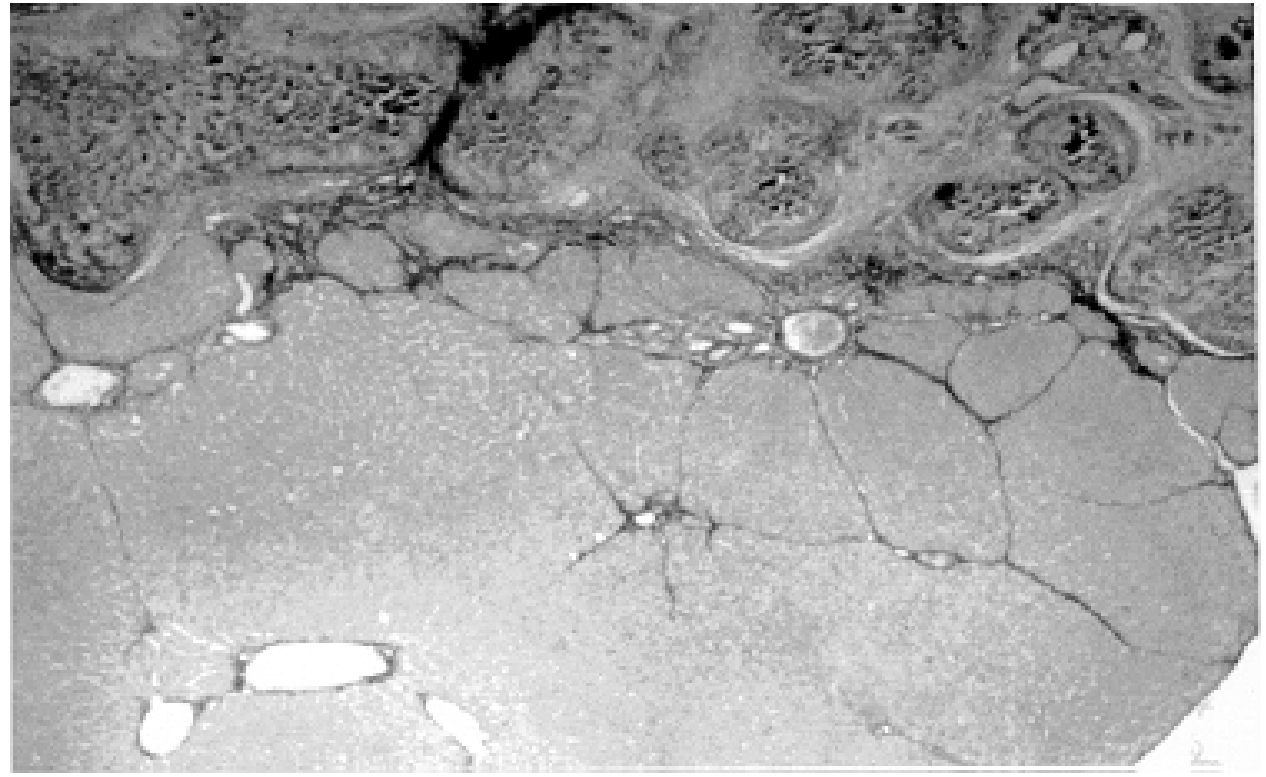

Fig. 2: numerous confluent parasite lesions caused by Capillaria hepatica in the rat liver are seen at the top of the picture, but septal fibrosis is minimal and only present at the immediate vicinity of the focal parasite lesion. The animal was treated with $800,000 \mathrm{IU}$ of interferon- $\alpha$ for 60 days. Sirius-red stain for collagen, $25 \mathrm{X}$

not loose weight or appetite, and did not differ in these aspects from the control rats receiving saline injections.

\section{DISCUSSION}

Septal fibrosis of the liver, associated with $C$. hepatica infection of rats, was clearly inhibited by interferon- $\alpha$ treatment. The anti-fibrogenic effect of the drug appeared dependent on the administration of high doses. As a matter of fact, the dose of 100,000 IU was first used in an attempt to reproduce the conditions in the paper by Moreno and Muriel (1995) in which fibrosis occurring in the model of total bile duct ligation in rats was successfully treated. Results were then slightly suggestive of an antifibrogenic effect, being statistically significant on 


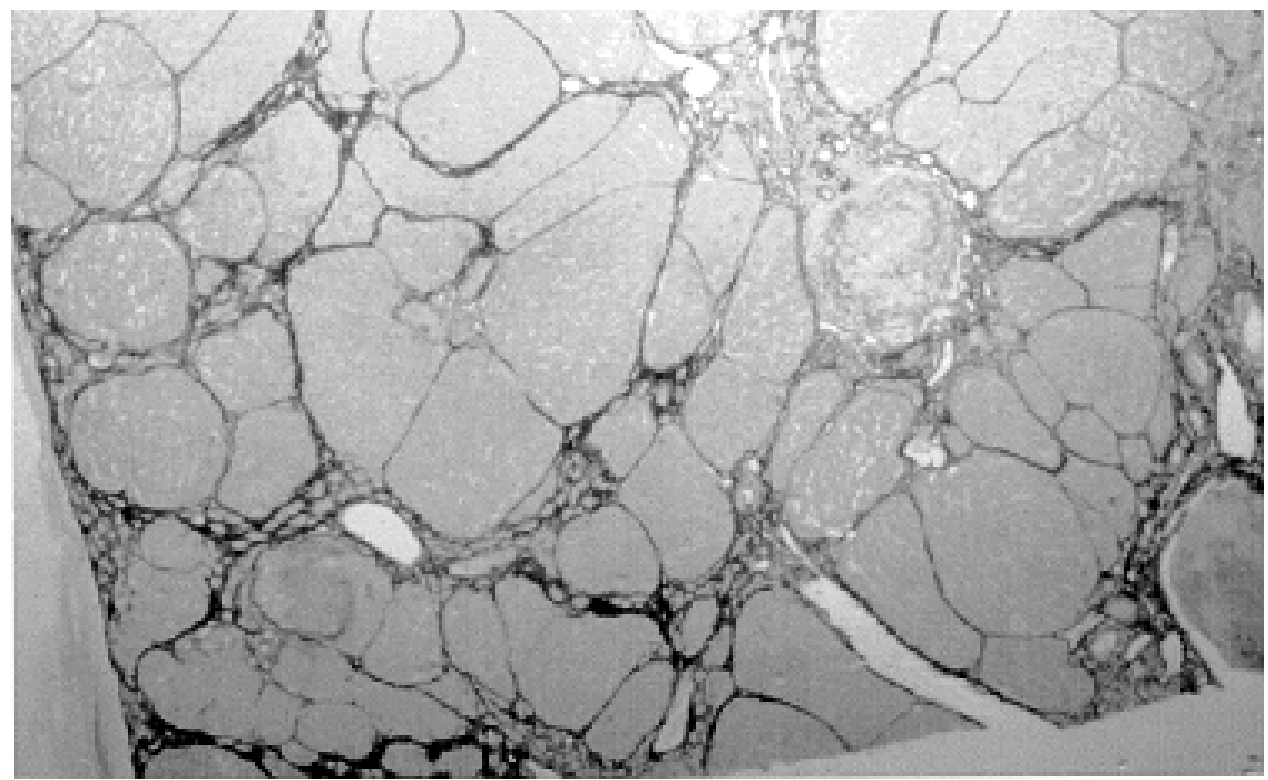

Fig. 3: control of interferon treatment. Septal fibrosis involves the entire liver and isolates nodular portion of the hepatic parenchyma, forming the picture of cirrhosis. A rounded residual fibrotic lesion, directly caused by Capillaria hepatica, is also present (arrows). Sirius-red stain for collagen, 25X

morphometric grounds only. Such discrepancy of results with different methods of fibrosis evaluation has also been observed in human studies when the anti-fibrotic effect was rather mild (Guerret et al. 1999). However, a clear-cut, dose-depend effect became evident when the animals were treated with 500,000 and 800,000 IU. The direct transposition

\section{TABLE I}

Semi-quantitative histological evaluation of fibrosis in rats with Capillaria hepatica-induced septal fibrosis of the liver after treatment with interferon- $\alpha(\mathrm{INF}-\alpha)$

\begin{tabular}{lccl}
\hline Groups & Biopsy & Autopsy & Treatment \\
\hline Control (n=5) & +++ & +++ & Saline (PBS) \\
Group I & & & INF- $\alpha$ (100,000UI) \\
Animal 1 & - & +++ & \\
Animal 2 & - & ++ & \\
Animal 3 & - & ++ & \\
Animal 4 & - & +++ & \\
Animal 5 & - & ++ & \\
Group II & & & INF- $\alpha$ (500,000 UI) \\
Animal 1 & +++ & ++ & \\
Animal 2 & ++ & + & \\
Animal 3 & ++ & ++ & \\
Group III & & & INF- $\alpha$ (800,000 UI) \\
Animal 1 & ++ & + & \\
Animal 2 & + & + & \\
Animal 3 & + & + & \\
Animal 4 & + & + & \\
Animal 5 & ++ & + & \\
\hline
\end{tabular}

TABLE II

Morphometric evaluation of hepatic fibrosis in rats with Capillaria hepatica-induced septal fibrosis of the liver

\begin{tabular}{lcl}
\hline Groups & Average $\left(\mu \mathrm{m}^{2}\right) / \mathrm{SD}$ & Treatment \\
\hline Control $(\mathrm{n}=5)$ & $19.28 \times 10^{4} \pm 2.17 \times 10^{4}$ & PBS $(0.85 \%)$ \\
I $(\mathrm{n}=5)$ & $13.41 \times 10^{4} \pm 5.5 \times 10^{4}$ & $\begin{array}{l}\text { INF- } \alpha \\
(100,000 \mathrm{UI})\end{array}$ \\
II $(\mathrm{n}=3)$ & $10.31 \times 10^{4} \pm 3.59 \times 10^{4}$ & $\begin{array}{l}\text { INF- } \alpha \\
(500,000 \mathrm{UI})\end{array}$ \\
III $(\mathrm{n}=5)$ & $5.69 \times 10^{4} \pm 2.74 \times 10^{4}$ & $\begin{array}{l}\text { INF- } \alpha \\
(800,000 \mathrm{UI})\end{array}$ \\
\hline
\end{tabular}

Differences between the control group and each one of the treated groups are highly significant $(\mathrm{P}<0.05$ Student-Newman-Keuls); INF- $\alpha$ : interferon- $\alpha$

\section{TABLE III}

Hydroxiproline content measured in the livers of rats with Capillaria hepatica-induced septal fibrosis treated with interferon- $\alpha$ (INF- $\alpha)$

\begin{tabular}{lll}
\hline Groups & $\begin{array}{c}\text { Average } \\
\mu \text { mol/g/SD }\end{array}$ & Treatment \\
\hline Control 4 (n=5) & $8.84 \pm 1.92$ & PBS $(0.85 \%)$ \\
I $(n=5)$ & $7.40 \pm 1.27$ & INF- $\alpha(100,000$ UI) \\
II $(n=3)$ & $4.13 \pm 1.38$ & INF- $\alpha(500,000$ UI) \\
III $(n=5)$ & $3.95 \pm 0.73$ & INF- $\alpha(800,000$ UI) \\
\hline
\end{tabular}

Differences between control (Group IV) and groups II and III are highly significant $(\mathrm{P}<0.05$, Student-NewmanKeuls) 
of these doses for human use is certainly not adequate, but present demonstration is still of interest. Human beings can tolerate doses of interferon$\alpha$ higher than 5 million units, although some adverse effects may become frequent. Effective doses and toxicities of drugs usually show large variations in different animal species. Demonstration of a dose-dependent effect of interferon on hepatic fibrosis may be important. Not only duration of treatment, but also the doses, are important factors observed for the anti-fibrotic effect of interferon- $\alpha$ in humans (Poynard et al. 1995, Degos et al. 1998). The side effects of interferons are not trivial, but effective interventions to reduce these effects may improve the quality of life of many patients (Cotler \& Jensen 1999).

A possible direct effect of interferon- $\alpha$ on $C$. hepatica can be discarded. This helminth causes a self-limited infection to rats, all adult worms dying within the liver around the 25th-40th day after infection. Later on the involuting focal parasitic lesions are scattered distributed throughout the liver, their number showing little variation from case to case during the present experiment. All control cases exhibited severe degree of fibrosis (cirrhosis) by the end of experiment, regardless possible variation in number of parasitic lesions. Therefore, parasite load did not seem an important factor to be considered in the present circumstances in order to evaluate the anti-fibrosis effects of interferon- $\alpha$.

The expression of $\alpha$-isotype of actin in Ito's cells was seen to be markedly depressed in patients with chronic hepatitis submitted to interferon$\alpha$ treatment, as immunohistochemically detected (Guido et al. 1996). This effect would interfere with the phenotype transformation of Ito's cells into myofibroblasts, a crucial step during extracellular matrix formation in the liver (Geerts et al. 1999).

Studies in vitro have demonstrated that interferon- $\alpha$ can also have other anti-fibrotic effects, such as increasing the synthesis of collagenases and glycosaminoglycan in cultured dermal fibroblats (and in interfering with cell-multiplication and collagen synthesis of cultured Ito's cells (Mallat et al. 1995, Geerts et al. 1999).

If septal hepatic fibrosis associated with $C$. hepatica infection in rats also depends on an immunological basis, the well known modulatory effect of interferon may be playing a role in preventing or degrading fibrosis in the experimental model now being considered.

\section{REFERENCES}

Andrade ZA 1991. Contribution to the study of septal fibrosis of the liver. Internat J Exper Pathol 72: 553562.

Bergman I, Loxley R 1963. Improved and simplified methods for the spectrophotometric determination of hydroxyproline. Ann Chem 35: 1961-1965.

Bhunchet E, Eishi Y, Wake K 1996. Contribution of immune response to the hepatic fibrosis induced by porcine serum. Hepatology 23: 811-817.

Cotler SJ, Jensen DM 1999. Management of chronic hepatitis C. In E Krawitt, Medical Menagement of Liver Disease, Marcel Decker, New York, p. 99-123.

Degos F, Daurat V, Chevret S, Gayno S, Bastie A, Riachi G, Bartolomei-Portal I, Barange K, Moussalli J 1998. Reinforced regimen of interferon alfa- $2 b$ reduces the incidence of cirrhosis in patients with chronic hepatitis C: a multicentric randomised trial. J Hepatol 29: 224-232.

Ferreira LA, Andrade ZA 1993. Capillaria hepatica: a cause of septal fibrosis of the liver. Mem Inst Oswaldo Cruz 88: 441-447.

Fort J, Pilette C, Veal N, Oberti F, Gallois Y, Douay O, Rosenbnaum J, Cales P 1998. Effects of long-term administration of interferon alpha in two models of liver fibrosis in rats. J Hepatol 29: 263-270.

Geerts A, De Bleser P, Hautekeete ML, Niki T, Wisse E 1999. Fat-storing (Ito) cell biology. In IM Arias, JL Boyer, N Fausto, WB Jakoby, DA Schachter, DA Shafritz (eds), The Liver: Biology and Pathobiology, 3rd ed., Raven Press, New York, p. 819-838.

Guerret S, Desmoulière A, Chossegros P, Costa AMA, Badid C, Trépo C, Grimaud JA, Chevallier M 1999. Long-term administration of interferon-a in non-responder patients with chronic hepatitis C: follow up of liver fibrosis over 5 years. J Viral Hepatol 6: 125133.

Guido M, Rugge M, Chemello L, Leandro G, Fattovich G, Giustina G, Cassaro M, Alberti A 1996. Liver stellate cells in chronic viral hepatitis: the effect of interferon therapy. J Hepatol 24: 301-307.

Horisberger MA, Staritzky K 1987. A recombinant human interferon- $\alpha$ B/D hybrid with a broad hostrange. J Gen Virol 68: 945-948.

Junqueira LCU, Bignolas G, Brentani R 1979. Picrosirius staining plus polarization microscopy, a specific method for collagen detection in tissue sections. Histochem J 11: 447-455.

Mallat A, Préaux AM, Blazejewski S, Rosenbaum J, Dhumeaux D, Mavier P 1995. Interferon $\alpha$ and $\gamma$ inhibit proliferation and collagen synthesis of human Ito cells in culture. Hepatology 21: 1003-1010.

Manabe N, Chevalier M, Chossegros P, Causse X, Guerret S, Trépo C, Grimaud JA 1993. Interferon $\alpha-2 b$ therapy reduces lver fibrosis in chronic nonA, non-B hepatitis: a quantitative histological evaluation. Hepatology 18: 1344-1349.

Meister A, Uzé G, Mogensen KE, Gresser I, Tovey MG, Grütter M, Meyer F 1986. Biological activities and receptor binding of two human recombinant interferons and their hybrids. J Gen Virol 67: 16331643.

Moreno MG, Muriel P 1995. Remission of liver fibrosis by interferon- $\alpha$. Biochem Pharmacol 50: 515-520.

Paronetto F, Popper H 1966. Chronic liver imjury induced by immunologic reactions. Cirrhosis following immunization with heterologous sera. Am J 
Pathol 40: 1087-1101.

Pilette C, Fort J, Rifflet H, Calés P 1997. Effects antifibrosants des interferon. Mécanismes d' action et perspectives thérapeutiques. Gastroenterol Clin Biol 21: 466-471.

Poynard T, Bedossa P, Chevalier M, Mathurim P, Lemonnier C, Trepo C, Couzigou P, Payen JL, Sajus M, Costa JM, Vidaud M, Chaput JC 1995. A comparison of three different alfa-2 regimens for the long-term treatment of chronic non-A, non-B hepatitis. Multicentric studiy group. New Engl J Med 332: 1457-1462.

Shiratori Y, Imazeki F, Moriyama M, Yano M, Arakawa Y, Yokosuka O, Kurori T, Nishiguchi S, Sata M, Yamada G, Fujiyama S, Yoshida H, Omata M 2000. Histologic improvement of fibrosis in patients with hepatitis $\mathrm{C}$ who have sustained response to interferon therapy. Ann Int Med 132: 517-524. 